\title{
Microbial Transformation of 5-Episinuleptolide
}

\author{
Haidy Nasr Kamel, ${ }^{* a}$ Frank Rolf Fronczek, ${ }^{b}$ Sherief Ibrahim Khalifa, ${ }^{c}$ and Marc Slattery ${ }^{a}$ \\ ${ }^{a}$ Department of Pharmacognosy and National Center for Natural Products Research, RIPS, School of Pharmacy, \\ University of Mississippi; University, MS 38677, U.S.A.: ${ }^{b}$ Department of Chemistry, Louisiana State University; Baton \\ Rouge, LA 70803-1804, U.S.A.: and ${ }^{c}$ Department of Pharmcognosy, Faculty of Pharmacy, Suez Canal University; \\ Ismailia, Egypt. Received October 7, 2006; accepted January 4, 2007
}

5-Episinuleptolide (1) is an abundant norcembranolide diterpene isolated from several species of the soft coral genus Sinularia. Biocatalytic transformation studies of 1 using Streptomyces lavendulea ATCC 8664 resulted in the isolation and characterization of two new metabolites 2 and 3. Compound 2, 6 $\alpha$-hydroxy-5-episinuleptolide was produced via a stereoselective reduction of 1 and was further metabolized into compound 3 which has a 3,8-bicylized cembranoid skeleton. The structures and configurations of the metabolites were determined by spectroscopic and $X$-ray crystallographic analyses.

Key words microbial transformation; Streptomyces lavendulea; cembranoid; Sinularia

Cembranoids have been reported to possess a wide range of biological activities including cytotoxic and anti-tumor properties. ${ }^{1)}$ They are diterpenes with 14 -membered macrocyclic rings and have been isolated from terrestrial as well as marine sources. Soft corals are a particularly rich source of cembrane and cembranolide lactone natural products. In 1979, Kobayashi et al. reported the isolation of two cembranoids, sarcophytol A and B from the soft coral Sarcophyton glaucum (Alcyonaria, Alcyoniidae). ${ }^{2)}$ These compounds attracted much attention owing to their ability to inhibit tumor promotion. ${ }^{3)}$ This prompted interest in targeting cembrane diterpenes in natural product isolation as well as semisynthesis to enhance their antitumor activity and reduce their toxicity. ${ }^{4-6)}$

Biocatalysis using microorganisms has proven useful in achieving chemical transformations that are difficult or impossible to achieve by conventional chemical reactions; it carries the advantage of stereo- as well as regioselectivity. ${ }^{7)}$ Biocatalysis has been utilized to convert natural cembranoids into a series of diverse metabolites with strong chemopreventive and antimetastatic activities, respectively. ${ }^{5,8)}$

5-Episinuleptolide (1) is a norcembranolide diterpene (a cembrane lacking the C-18 methyl group at C-4) first isolated from the soft coral Sinularia leptoclados by an Australian group ${ }^{9)}$ and later from several other species. The relative configuration derived by NMR spectroscopic data was confirmed by X-ray diffraction analysis. However, the structure was drawn in error showing the configuration at C-11 opposite to what had been established by the crystal structure. ${ }^{10)}$ Misinterpretation of the X-ray data and of the configuration at $\mathrm{C}-11$ has led to confusion in the literature, and this error has been propagated in many of the later papers ${ }^{11,12}$ and reviews. ${ }^{13)}$ Sato et al. reported the $\mathrm{C}-11$ epimer $^{14)}$ and Shoji et al. reported its C-5 epimer and named it sinuleptolide, ${ }^{15)}$ hence the name 5-episinuleptolide for compound $\mathbf{1}$. Recently, Tseng et al. isolated and determined unambiguously the absolute configuration of 5-episinuleptolide (1) by a modified Mosher's method as $1 R, 5 S, 8 R, 10 S, 11 R^{16)} 5$ Episinuleptolide showed moderate cytotoxicity in our assays against four human cancer cell lines. In addition, it was shown to have an inhibitory effect on LPS-induced TNF- $\alpha$ production. ${ }^{17)}$

We have isolated compound $\mathbf{1}$ from both Sinularia maxima and the hybrid Sinularia maxima $\times S$. polydactyla in good yield (ca. $0.5 \%$ of the extract in both cases). The structure was determined via NMR analysis and confirmed by X-ray diffraction analysis and the Mosher's method. This study aims at using biocatalyis to generate structurally diverse analogues of 5-episinuleptolide (1) and evaluating their cytotoxic properties.

\section{Results and Discussion}

Thirty-two growing cultures of bacteria and fungi were screened for their ability to catalyze the biotransformation of 5-episinuleptolide (1). Several cultures were able to convert 1 into two or three metabolites and some of the cultures metabolized the substrate completely producing only trace amounts of the TLC detectible metabolites. The actinomycete Streptomyces lavendulae ATCC 8664 was chosen for preparative scale fermentation of $\mathbf{1}$ and compounds $\mathbf{2}$ and $\mathbf{3}$ were isolated from the fermentation mixture.

Compound $2(30 \mathrm{mg})$ was obtained in $7.5 \%$ yield as a crystalline solid. On the basis of its HR-ESI-MS at $\mathrm{m} / \mathrm{z}$ $373.1534[\mathrm{M}+\mathrm{Na}]^{+}$and ${ }^{1} \mathrm{H}-$ and ${ }^{13} \mathrm{C}-\mathrm{NMR}$ spectroscopic data, the molecular formula of 2 was established as $\mathrm{C}_{19} \mathrm{H}_{26} \mathrm{O}_{6}$ with seven degrees of unsaturation. The structure was determined mainly by comparison of its ${ }^{13} \mathrm{C}$-NMR spectra with that of 5-episinuleptolide (1). Compound 2 lacked the carbonyl carbon at $\delta 216.3$ assigned to C-6 in $\mathbf{1}$ whilst it exhibited an extra oxygenated methine carbon at $\delta 72.1$ (Table 1). This data suggested that the carbonyl ketone at C-6 in $\mathbf{1}$ had been selectively reduced to a hydroxyl group. An NOE corre-
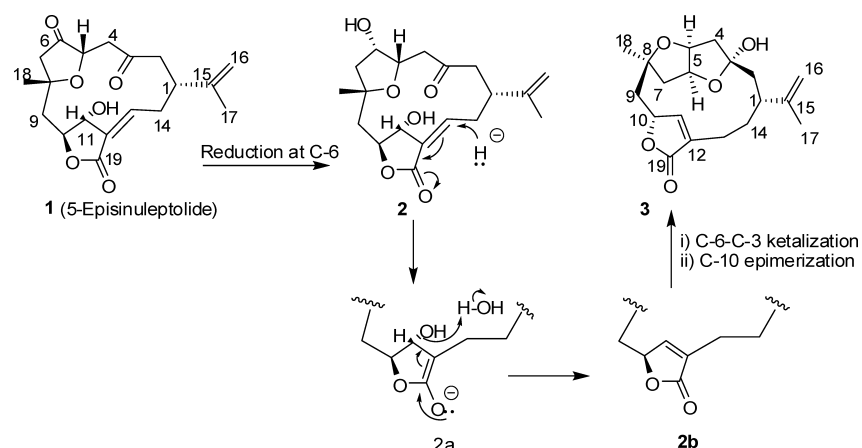

Chart 1 
Table 1. ${ }^{13} \mathrm{C}$-NMR Data of Compounds $\mathbf{1}, \mathbf{2}$ and $\mathbf{3}$

\begin{tabular}{rrrr}
\hline \hline Pos. & $\mathbf{1}^{a)}$ & $\mathbf{2}^{b)}$ & $\mathbf{3}^{c)}$ \\
\hline 1 & 39.2 & 38.9 & 40.3 \\
2 & 44.1 & 45.2 & 35.5 \\
3 & 206.5 & 208.7 & 113.2 \\
4 & 45.4 & 43.5 & 41.5 \\
5 & 75.4 & 77.0 & 84.5 \\
6 & 216.3 & 72.1 & 80.9 \\
7 & 51.5 & 48.8 & 38.9 \\
8 & 79.4 & 80.3 & 84.2 \\
9 & 42.6 & 43.0 & 38.5 \\
10 & 83.8 & 83.8 & 79.6 \\
11 & 74.9 & 75.6 & 149.6 \\
12 & 133.6 & 132.8 & 132.3 \\
13 & 142.7 & 143.8 & 21.6 \\
14 & 27.5 & 27.5 & 30.5 \\
15 & 148.0 & 147.7 & 148.1 \\
16 & 110.8 & 109.7 & 111.5 \\
17 & 22.5 & 21.1 & 18.0 \\
18 & 26.6 & 26.5 & 27.6 \\
19 & 169.3 & 170.2 & 174.8 \\
& & & \\
\hline & & &
\end{tabular}

a) Spectra recorded at $600 \mathrm{MHz}$ in DMSO- $d_{6}, b$ ) in $\mathrm{CD}_{3} \mathrm{OD}, c$ ) in $\mathrm{C}_{6} \mathrm{D}_{6}$. Chemical shifts values are in parts per million relative to TMS.

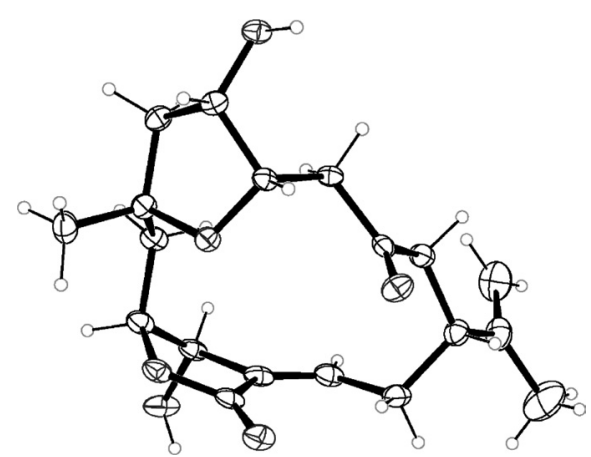

Fig. 1a. Perspective Drawing of the X-Ray Structure of Compound 2 (Conformation 1)

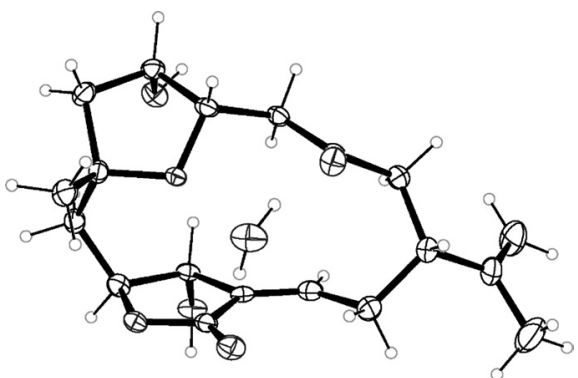

Fig. 1b. Perspective Drawing of the X-Ray Structure of Compound 2 (Conformation 2, Coupled with a Molecule of Water)

lation between H-6 $(\delta 4.28)$ and Me-18 $(\delta$ 1.29) indicated an $\alpha$-orientation of the C-6 hydroxyl functionality. Compound 2 readily crystallizes from a mixture of acetone and hexane. An X-ray crystallographic analysis of the monohydrate was undertaken. A perspective drawing of $\mathbf{2}$ is given in Fig. 1, which confirmed the structure deduced by NMR studies as $6 \alpha$-hydroxy-5-episinuleptolide (Tables 1,2 ). The X-ray diffraction analysis data indicated that the molecule exists in two different conformations in the solid state (Figs. 1a, b, Table 3).
Table 2. ${ }^{1} \mathrm{H}-\mathrm{NMR}$ Data of Compounds $\mathbf{1}, \mathbf{2}$ and $\mathbf{3}(\boldsymbol{\delta}$, Mult, $J(\mathrm{~Hz}))$

\begin{tabular}{|c|c|c|c|}
\hline $\mathrm{H}$ & $\mathbf{1}^{a)}$ & $\mathbf{2}^{b)}$ & $3^{c)}$ \\
\hline 1 & $2.52(\mathrm{~m})$ & $2.84(\mathrm{~m})$ & $2.04(\mathrm{brt}, 9)$ \\
\hline \multirow[t]{2}{*}{2} & $2.47(\mathrm{~m})$ & $2.40(\mathrm{dd}, 15.0,2)$ & $1.22(\mathrm{brd}, 13.8)$ \\
\hline & $2.63(\mathrm{dd}, 15,2.4)$ & $2.83($ br d, 15.0$)$ & $1.74(\mathrm{brt}, 7)$ \\
\hline \multicolumn{4}{|l|}{3} \\
\hline \multirow[t]{2}{*}{4} & $2.44(\mathrm{~d}, 15)$ & $2.0(\mathrm{dd}, 14.7,4.5)$ & $2.13(\mathrm{~d}, 14.4)$ \\
\hline & $2.71(\mathrm{~m})$ & $2.18(\mathrm{brd}, 6.5)$ & $1.96(\mathrm{brd}, 7.2)$ \\
\hline 5 & $4.15(\mathrm{dd}, 10.2,2.4)$ & $4.30(\mathrm{dd}, 4.5,2.4)$ & $4.14(\mathrm{brt}, 7.2)$ \\
\hline 6 & & $4.28(\mathrm{~m})$ & $4.15(\mathrm{~m})$ \\
\hline \multirow[t]{2}{*}{7} & $2.41(\mathrm{~d}, 18)$ & $1.99(\mathrm{dd}, 14.0,5)$ & $1.43(\mathrm{~m})$ \\
\hline & $2.51(\mathrm{~m})$ & 2.08 (br dd, 14.0, 6.6) & $1.66(\mathrm{brd}, 13.2)$ \\
\hline \multicolumn{4}{|l|}{8} \\
\hline \multirow[t]{2}{*}{9} & $2.33(\mathrm{dd}, 15,7.2)$ & $2.41(\mathrm{br} \mathrm{dd}, 16,2.4)$ & $1.92(\mathrm{~m})$ \\
\hline & $2.07(\mathrm{dd}, 15,2.4)$ & $2.86(\mathrm{~m})$ & $1.80(\mathrm{~m})$ \\
\hline 10 & $4.40(\mathrm{~d}, 7.2)$ & 4.50 (brt, 6.6) & 4.40 (brs) \\
\hline 11 & $4.43(\mathrm{~d}, 4)$ & 4.60 (brs) & $6.80(\mathrm{brs})$ \\
\hline \multicolumn{4}{|l|}{12} \\
\hline \multirow[t]{2}{*}{13} & $6.25(\mathrm{dd}, 11,3)$ & $6.47(\mathrm{dd}, 11.4,4.2)$ & $2.36(\mathrm{dd}, 12.8,5.7)$ \\
\hline & & & $1.85($ brt, 13.0$)$ \\
\hline \multirow[t]{2}{*}{14} & $2.02(\mathrm{brd}, 15.6)$ & $1.80(\mathrm{~m})$ & $1.62(\mathrm{brt}, 13.5)$ \\
\hline & $3.55($ ddd $15.6,11,6)$ & $2.16(\mathrm{~m})$ & $1.50(\mathrm{~m})$ \\
\hline \multicolumn{4}{|l|}{15} \\
\hline \multirow[t]{2}{*}{16} & 4.80 (brs) & $4.81(\mathrm{~s})$ & 4.71 (brs) \\
\hline & $4.82(\mathrm{brs})$ & $4.83(\mathrm{~s})$ & 4.73 (brs) \\
\hline 17 & 1.75 (brs) & $1.82(\mathrm{brs})$ & 1.43 (brs) \\
\hline 18 & $1.28(\mathrm{~s})$ & $1.29(\mathrm{~s})$ & $0.67(\mathrm{~s})$ \\
\hline 19 & & & \\
\hline
\end{tabular}

a) Spectra recorded at $600 \mathrm{MHz}$ in DMSO, b) in $\mathrm{MeOD}, c$ ) in $\mathrm{C}_{6} \mathrm{D}_{6}$. Chemical shifts values are in parts per million relative to TMS.

Compound 3 was obtained as a crystalline solid $(2 \mathrm{mg})$ in $0.5 \%$ yield. HR-ESI-MS at $m / z 357.1676[\mathrm{M}+\mathrm{Na}]^{+}$established the molecular formula of $\mathbf{3}$ as $\mathrm{C}_{19} \mathrm{H}_{26} \mathrm{O}_{5}$. The ${ }^{13} \mathrm{C}$ NMR spectrum in $\mathrm{C}_{6} \mathrm{D}_{6}$ showed resonances for 19 carbon atoms differentiated by DEPT into five quaternary carbons, six methines, six methylenes and two methyl groups. The ${ }^{13} \mathrm{C}$-NMR spectrum of $\mathbf{3}$ exhibited similar features to compound 2. It indicated the presence of four olefinic carbons resonating at $\delta 111.5,132.3,148.1$, and 149.6, a lactone carbonyl at $\delta 174.8$ and resonances assigned to the isopropenyl functionality at $\mathrm{C}-1$ as in $\mathbf{1}$ and $\mathbf{2}$. It also revealed the absence of the ketone carbonyls resonating at $\delta 206.5$ and 216.3 in $\mathbf{1}$. Additionally, the ${ }^{13} \mathrm{C}$-NMR spectrum of $\mathbf{3}$ exhibited an additional methylene carbon at $\delta 21.6$ assigned to $\mathrm{C}-13$ in 3 . Thus, the ${ }^{13} \mathrm{C}-\mathrm{NMR}$ resonance at $\delta 21.6$ was correlated in the HMQC spectrum with the protons at $\delta 1.85(1 \mathrm{H}$, brt, $J=13.0 \mathrm{~Hz})$ and $\delta 2.36(1 \mathrm{H}, \mathrm{dd}, J=13.0,5.7 \mathrm{~Hz})$. This latter resonance showed in the HMBC spectrum long range correlation with the methylene at $\delta 30.5$ (C-14), the methine carbon at $\delta 40.3(\mathrm{C}-1)$, the fully substituted carbon at $\delta 132.3$ $(\mathrm{C}-12)$ and the olefinic $\mathrm{C}-11$ at $\delta$ 149.6. This structural feature suggested an allylic rearrangement at the exocyclic $\alpha, \beta$ unsaturated $\gamma$-lactone moiety. Thus, the endocyclic proton (H-11) in 3 resonates at $\delta 6.80$ while $\mathrm{H}-13$ on the exocyclic $\alpha, \beta$-unsaturated $\gamma$-lactone resonates at $\delta 6.25$ in 1 and at $\delta$ 6.47 in 2 . Another characteristic feature of the ${ }^{13} \mathrm{C}-\mathrm{NMR}$ spectrum of $\mathbf{3}$ is the presence of a quaternary non-olefinic carbon resonating at $\delta 113.2$ suggesting a hemiketal functionality. The above structural features accounted for six degrees of unsaturation and therefore compound $\mathbf{3}$ had to contain an additional ring. Analysis of the HMBC and COSY correlations (Fig. 2) defined structure $\mathbf{3}$ as shown. Confirma- 
Table 3. Crystal Data, Data Collection and Refinement Parameters

\begin{tabular}{|c|c|c|c|}
\hline Compound & 5-Episinuleptolide, $\mathbf{1}$ & 2 & 3 \\
\hline CCDC deposit no. & CCDC 206652 & CCDC 608111 & CCDC 608112 \\
\hline Formula & $\mathrm{C}_{19} \mathrm{H}_{24} \mathrm{O}_{6}$ & $\mathrm{C}_{19} \mathrm{H}_{26} \mathrm{O}_{6} \cdot \mathrm{H}_{2} \mathrm{O}$ & $\mathrm{C}_{19} \mathrm{H}_{26} \mathrm{O}_{5}$ \\
\hline Color/shape & Colorless lath & Colorless needle & Colorless needle \\
\hline Formula weight & 348.38 & 368.41 & 334.40 \\
\hline Crystal system & Monoclinic & Trigonal & Orthorhombic \\
\hline Space group & $P 2_{1}$ & $P 3_{1}$ & $P 2_{1} 2_{1} 2_{1}$ \\
\hline Temp., K & 100 & 100 & 100 \\
\hline \multicolumn{4}{|l|}{ Cell constants } \\
\hline$a, \AA$ & $11.4988(10)$ & $16.206(3)$ & $6.4990(10)$ \\
\hline$b, \AA$ & $6.0562(4)$ & $16.206(3)$ & $10.439(2)$ \\
\hline$c, \AA$ & $12.5310(14)$ & $12.517(2)$ & $25.321(5)$ \\
\hline$\beta$, deg. & $98.641(4)$ & - & - \\
\hline Cell volume, $\AA^{3}$ & $862.74(13)$ & $2847.0(9)$ & $1717.9(5)$ \\
\hline Formula units/unit cell & 2 & 6 & 4 \\
\hline$D_{\text {calc }}, \mathrm{g} \mathrm{cm}^{-3}$ & 1.341 & 1.289 & 1.293 \\
\hline$\mu_{\text {calc }}, \mathrm{cm}^{-1}$ & 0.99 & 0.98 & 0.92 \\
\hline Diffractometer/scan & Nonius KappaCCD/ $\omega$ & Nonius KappaCCD/ $\omega$ & Nonius KappaCCD $/ \omega$ \\
\hline Radiation, graphite monochr. & $\operatorname{Mo} K \alpha(\lambda=0.71073 \AA)$ & $\operatorname{MoK} \alpha$ & $\operatorname{Mo} K \alpha$ \\
\hline Crystal dimensions, $\mathrm{mm}$ & $0.01 \times 0.10 \times 0.75$ & $0.05 \times 0.07 \times 0.48$ & $0.05 \times 0.07 \times 0.55$ \\
\hline Reflections measured & 6050 & 58082 & 6703 \\
\hline$R_{\text {int }}$ & 0.045 & 0.042 & 0.041 \\
\hline Independent reflections & 1654 & 4711 & 2279 \\
\hline $2 \theta$ range, deg & $5.0<2 \theta<50.0$ & $5.0<2 \theta<56.6$ & $5<2 \theta<55.0$ \\
\hline Range of $h, k, l$ & $\pm 13, \pm 7, \pm 14$ & $\pm 21, \pm 18, \pm 16$ & $\pm 8, \pm 13, \pm 32$ \\
\hline Reflections observed & 1275 & 3779 & 1777 \\
\hline Criterion for observed & $I>2 \sigma(I)$ & $I>2 \sigma(I)$ & $I>2 \sigma(I)$ \\
\hline Data/parameters & $1654 / 230$ & $4711 / 498$ & $2279 / 222$ \\
\hline$R$ (obs) & 0.040 & 0.046 & 0.044 \\
\hline$R$ (all data) & 0.064 & 0.068 & 0.066 \\
\hline$R_{\mathrm{w}}, F^{2}$ (all data) & 0.078 & 0.075 & 0.088 \\
\hline $\mathrm{H}$ atom treatment & Constrained & OH refined & Constrained \\
\hline GOF & 1.029 & 1.046 & 1.027 \\
\hline Max resid. peaks $\left(\mathrm{e} \AA^{-3}\right)$ & $0.18,-0.18$ & $0.22,-0.20$ & $0.19,-0.20$ \\
\hline
\end{tabular}

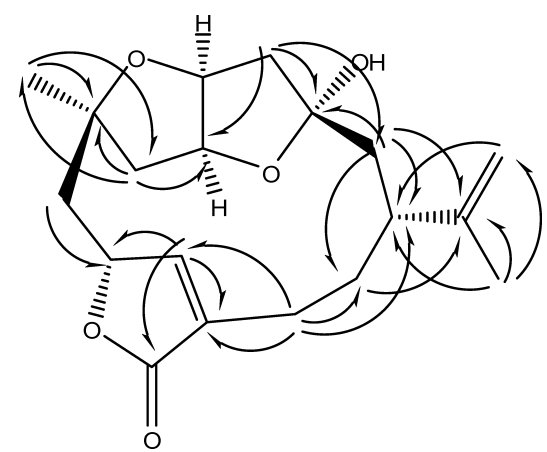

Fig. 2. HMBC Correlations of Compound 3

tion of the proposed structure as well as the determination of the configuration was achieved independently via X-ray diffraction analysis (Fig. 3, Table 3). Metabolite 3 represents a new nor-diterpene having a 3,8-bicyclized cembranoid skeleton.

Further inspection of the chemical structures of metabolites $\mathbf{2}$ and $\mathbf{3}$ suggested that compound $\mathbf{3}$ could be produced from metabolite 2 via hemiketalization involving the C-6 hydroxy and C-3 carbonyl functionalities. When compound 2 was fed to liquid culture of S. lavendulea, using the two stage fermentation technique as used with $\mathbf{1}$, compound $\mathbf{3}$ was detected in the fermentation mixture indicating that $\mathbf{2}$ is indeed a precursor of 3. A parallel $\mathrm{pH}$-control experiment was done in order to rule out an artifactual explanation for the forma-

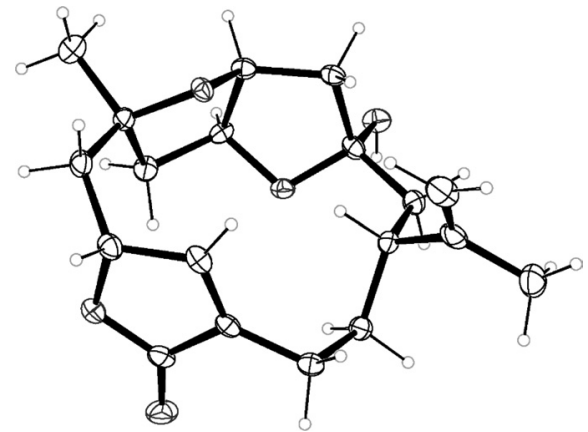

Fig. 3. Perspective Drawing of the X-Ray Structure of Compound 3

tion of 3. The above data suggests that 5-episinuleptolide (1) was initially reduced to $6 \alpha$-hydroxy-5-episinuleptolide (2) which underwent further metabolism to compound 3. Such metabolism might plausibly involve a dehydration/rearrangement sequence via intermediate $\mathbf{2 a}$. Intermediate $\mathbf{2 b}$ may then be susceptible to an epimerization at $\mathrm{C}-10$ due to the allylic nature of the $\mathrm{C}$-10 functional group, in a $\gamma$-position relative to the $\alpha, \beta$-unsaturated lactone moiety. ${ }^{18)}$

$6 \alpha$-Hydroxy-5-episinuleptolide (2) was shown to be less active than 5-episinuleptolide (1) in the cytotoxicity assay but was not toxic to Vero cells. The standard, doxyrubicin, was an order of magnitude more bioactive than any of these metabolites.

Our microbial transformation results have added to our un- 
derstanding of the metabolic capabilities of $S$. lavendulae. It has been reported that most of the reactions catalyzed by Streptomyces are oxidative in nature and include hydroxylation, $\mathrm{O}-, \mathrm{N}-$ and $\mathrm{S}-o x i d a t i o n s, \mathrm{C}-\mathrm{C}$ fission and $\mathrm{O}-$ and $\mathrm{N}-$ dealkylations. ${ }^{19,20)}$ Recently, the ability of a Streptomyces sp. (S. thermocyaneoviolaceus) to reduce aliphatic and aromatic $\alpha$-keto esters has been reported. ${ }^{21)}$ Our data indicates that $S$. lavendulae selectively reduces the carbonyl ketone to a hydroxyl, which is then susceptible to hemiketalization. These data support earlier results on the ability of actinomycetes to perform reduction reactions.

\section{Experimental}

General Experimental Procedures Optical rotations were measured with a JASCO DIP-370 digital polarimeter. UV spectra were measured on a Hewlett Packard 8452A Diode Array spectrometer. IR spectra were recorded on an ATI Mattson Genesis series FTIR spectrometer. NMR spectra were measured on Bruker Advance DRX-400 and DRX-500 spectrometers. ${ }^{1} \mathrm{H}-$ and ${ }^{13} \mathrm{C}$-NMR spectra were measured and reported in ppm by using the residual solvent peak as an internal standard. ESI-FT-MS analyses were measured on a Bruker-Magnex BioAPEX 30es ion cyclotron HR. Silica gel (Kieselgel 60, 32-36 $\mu \mathrm{m}$ ) was used for open column chromatography. Column chromatography fractions were monitored by TLC (silica gel $60, \mathrm{~F}_{254}$, Merck).

Animal Material The soft coral was collected from Piti Bomb holes, Guam and identified by M. Slattery.

Isolation of 5-Episinuleptolide The frozen soft coral was exhaustively extracted with methanol: dichloromethane $(1: 1)$ and the combined solvent extracts were concentrated under reduced pressure. The extract was subjected to silica gel vacuum liquid chromatography eluted with hexane, hexane-ethyl acetate, ethyl acetate-methanol to methanol to yield 11 fractions which were concentrated under reduced pressure. 5-Episinuleptolide was crystallized from the fraction eluted with $80 \%$ ethyl acetate : hexane. Crystals were washed successively with chloroform and methanol.

Microorganisms and Culture Collection The microorganisms used for the biotransformation studies were obtained from the Department of Pharmacognosy, University of Mississippi culture collection and Northen Regional Research Laboratories, Peoria, IL, U.S.A. They which were maintained as refrigerated agar slants at $4{ }^{\circ} \mathrm{C}$ and grown as recommended.

Biotransformation Experiments Initial screening was carried out using 32 microorganisms in a two-stage fermentation procedure. In this procedure, a stock culture kept on agar slants at $4{ }^{\circ} \mathrm{C}$ is inoculated into $25 \mathrm{ml}$ of sterile complex culture medium, compound medium $\alpha$, contained in a 125 $\mathrm{ml}$ Erlenmeyer flask capped with stainless steel caps. The flask is allowed to shake on a gyrotatory shaker at room temperature for $2 \mathrm{~d}$ or until good growth is established (stage I). About $2 \mathrm{ml}$ of the stage I culture was then aseptically transferred to $25 \mathrm{ml}$ of a fresh sterile culture medium in a new $125-\mathrm{ml}$ capped Erlenmeyer flask. After $24 \mathrm{~h}, 25-50 \mu \mathrm{l}$ of a $10 \%$ solution of the substrate was dissolved in dimethylformamide and added to the stage II culture and left on the shaker for a period of two weeks. Sampling was done by periodically withdrawing $2 \mathrm{ml}$ of the liquid culture, homogenizing and extracting the aliquots with ethyl acetate, and monitoring the course of biotransformation with TLC. A culture control and a substrate control were run synchronously with the fermentation. The TLC was done by spotting the extract of the culture blank next to the extract of the culture with compound added. The plates were visualized using UV light $(254 \mathrm{~nm})$ and vanillin/sulfuric acid spray reagent. A $\mathrm{pH}$-control experiment was also performed with S. lavendulea in which the substrate was added to a sterilized stage I culture. Scale-up was performed using 81 flasks each containing $500 \mathrm{ml}$ of $\alpha$-media and $50 \mathrm{mg}$ of the substrate. After incubation for $14 \mathrm{~d}$, the fermentation is stopped and the fermentation mixture is extracted.

Isolation of the Metabolites The fermentation mixture was extracted with ethyl acetate $(\times 3)$ and once with butanol/ethyl acetate $(1: 1)$. The extracts were combined and dried under vacuum $(1.5 \mathrm{~g})$. The extract was subjected to a VLC using a gradient elution of chloroform/methanol to yield 5 fractions. Fraction 2 eluted with $5 \%$ methanol/chloroform was further subjected to VLC using a gradient elution of acetone/hexane. Compound $\mathbf{2}$ was obtained by crystallization from the fraction eluted with acetone/hexane $(1: 1)$ while metabolite 3 was obtained by crystallization from the fraction eluted with acetone/hexane $(3: 7)$

Cytotoxicity Assay Compounds $\mathbf{1}$ and $\mathbf{2}$ were tested against the human tumor cell lines SK-MEL (malignant, melanoma), KB (Epidermal carcinoma, oral), BT-549 (Ductal carcinoma, breast) and SK-OV-3 (human oval carcinoma). The assay was performed according to the procedures published before. $^{22)}$

5-Episinuleptolide (1): White needles. $[\alpha]_{\mathrm{D}}^{25}-71.4^{\circ}(c=0.68, \mathrm{MeOH})$. ${ }^{1} \mathrm{H}-\mathrm{NMR}$ (DMSO- $d_{6}, 600 \mathrm{MHz}$ ): see Table $2 .{ }^{13} \mathrm{C}-\mathrm{NMR}$ (DMSO): see Table 1.

Metabolite (2): Colorless needles. $[\alpha]_{\mathrm{D}}^{25}+9.5^{\circ}(c=0.88, \mathrm{MeOH}) .{ }^{1} \mathrm{H}-$ NMR $\left(\mathrm{CD}_{3} \mathrm{OD}, 400 \mathrm{MHz}\right)$ : see Table $2 .{ }^{13} \mathrm{C}-\mathrm{NMR}\left(\mathrm{CD}_{3} \mathrm{OD}, 100 \mathrm{MHz}\right)$ : see Table 1. IR ( $\mathrm{NaCl}$ pellet) $\mathrm{cm}^{-1}: 3403,2934,2359,1743,1672,1644,1377$, 1176, 1050. UV $\lambda_{\max }(\mathrm{MeOH}) \mathrm{nm}(\log \varepsilon): 201$ (4.08), 219 (4.11). HR-ESIFT-MS $m / z$ : $373.1534[\mathrm{M}+\mathrm{Na}]^{+}$(Calcd for $\mathrm{C}_{19} \mathrm{O}_{6} \mathrm{H}_{26}+\mathrm{Na}, 373.1627$ ).

Metabolite (3): Colorless needles. $[\alpha]_{\mathrm{D}}^{25}-14.9^{\circ}(c=0.16, \mathrm{MeOH}) .{ }^{1} \mathrm{H}-$ NMR $\left(\mathrm{C}_{6} \mathrm{D}_{6}, 400 \mathrm{MHz}\right)$ : see Table $2 .{ }^{13} \mathrm{C}-\mathrm{NMR}\left(\mathrm{C}_{6} \mathrm{D}_{6}, 100 \mathrm{MHz}\right)$ : see Table 1. UV $\lambda_{\max }(\mathrm{MeOH}) \mathrm{nm}(\log \varepsilon): 202$ (4.22). 207 (4.1). HR-ESI-FT-MS $m / z$ : $357.1676[\mathrm{M}+\mathrm{Na}]^{+}$(Calcd for $\left.\mathrm{C}_{19} \mathrm{O}_{5} \mathrm{H}_{26}+\mathrm{Na}, 357.1677\right)$.

Acknowledgments The authors would like to thank Dr. S. Khan for running the cytotoxicity assay, Dr. C. D. Hufford for his helpful discussions and Dr. D. Ferreira for his thorough review of the manuscript.

\section{References and Notes}

1) Kamel H. N., Slattery M., Pharmaceutical Biol., 43, 1-17 (2005).

2) Kobayashi M., Nakagawa T., Mitsuhashi H., Chem. Pharm. Bull., 27, 2382-2387 (1979).

3) Fujiki H., Suganuma M., Suguri H., Yoshizawa S., Takagi K., Kobayashi M., J. Cancer Res. Clin. Oncology, 49, 25-28 (1989).

4) Katsuyama I., Fahmy H., Zajwony J. K., Khalifa S. I., Kilada R. W., Konoshima T., Takasaki M., Tokuda H., J. Nat. Prod., 65, 1809-1814 (2002).

5) El Sayed K. A., Hamann M. T., Waddling C. A., Jensen C., Lee S. K., Dunstan C. A., Pezzuto J. M., J. Org. Chem., 63, 7449-7455 (1998).

6) Sawant S. S., Sylvester P. W., Avery M. A., Desai P., Youssef D. T. A., El Sayed K. A., J. Nat. Prod., 67, 2017-2023 (2004).

7) Riva S., Curr. Opinion Chem. Biol., 5, 106-111 (2001).

8) Sawant S. S., Youssef D. T. A., Riland J, Ferniz M., Marchetti D., El Sayed K. A., J. Nat. Prod., 69, 1010-1013 (2006).

9) Bowden B. F., Coll J. C., Mitchell S. J., Mulder J., Stokie G. J., Aust. J. Chem., 31, 2049-2056 (1978).

10) Turner K. E., Bowden B. F., Stokie G. J., Howard C. J., Acta Cryst., B35, 1283-1284 (1979).

11) Lakshmi V., Schmitz F. J., J. Nat. Prod., 49, 728 -730 (1986).

12) Duh C., Hou R., Wang S., Chang T., Chin. Pharm. J., 45, 399-407 (1993).

13) Wahlberg I., Eklund A., Prog. Chem. Org. Natural Products, 59, 141-294 (1992).

14) Sato A., Fenical W., Qi-tai Z., Clardy J., Tetrahedron, 41, 4303-4308 (1985).

15) Shoji N., Umeyama A., Arihara S., J. Nat. Prod., 56, 1651-1653 (1993).

16) Tseng Y., Atallah A. F., Dai C., Chiang M. Y., Sheu J., Org. Lett., 7, 3813-3816 (2005).

17) Takaki H., Koganemaru R., Iwakawa Y., Higuchi R., Miyamato T., Biol. Pharm. Bull., 26, 380-382 (2003).

18) The sequence of these events is unkown.

19) Kieslich K., "Microbial Transformation of Non-steroid Cyclic Compounds," John Wiley \& Sons, New York, 1976.

20) Sariaslani F. S., Trower M. K., Buchholz S. E., Dev. Ind. Microbiol., 30, 161-170 (1989).

21) Ishihara K., Yamaguchi H., Hamda H., Nakajima N., Nakamura K., J. Mol. Catalysis B: Enzymatic, 10, 429-434 (2000).

22) Muhammad I., Bedir E., Khan S., Tekwani B. L., Khan I. A., Takamatsu S., Pelletier J., Walker L. A., J. Nat. Prod., 67, 772-777 (2004). 